\title{
A corpus-based study of phrasal verbs: CARRY OUT, FIND OUT, and POINT OUT
}

\author{
Kiativutikul, Choorit $\unrhd$ \\ Thammasat University, Thailand (chooritk@yahoo.com) \\ Phoocharoensil, Supakorn \\ Thammasat University, Thailand (Yhee143@gmail.com)
}

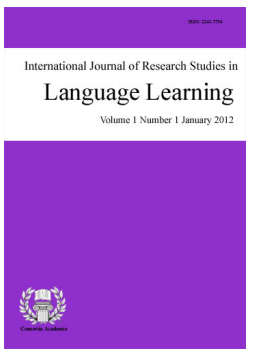

ISSN: 2243-7754 Online ISSN: 2243-7762

OPEN ACCESS

\section{Abstract}

This study, which is exploratory and corpus-based research, aims to investigate the grammatical patterns and the collocates of three phrasal verbs (PVs) in English, i.e., carry out, find out, and point out. They were chosen because the combination of the lexical verbs carry, find, and point, and the adverbial particle out put the three PVs among the top 50 PVs in the British National Corpus or BNC (Gardner \& Davies, 2007), and in the Corpus of Contemporary American English or COCA (Liu, 2011). A total of 500 concordance lines were searched from COCA for each PV, and were then placed in an Excel spreadsheet for analysis. Oxford Advanced Learner's Dictionary (OALD, 2010) was used as the main reference for information about the definitions of the target PVs, as well as grammatical information and collocates. The results reveal that although most of the grammatical patterns found in this study seem to be in accordance with those displayed in OALD (2010), certain patterns are not provided in the dictionary. The reason could be the limited space of the dictionary and users' stylistic variation in PV use. Regarding the collocates of the target PVs, most of them are lexical collocation, such as nouns, pronouns, and wh-words, followed by grammatical collocation, such as preposition. Pedagogically speaking, the corpus-based data could help provide additional information not illustrated in dictionaries. In addition, learners can explore the language patterns and search for naturally-occurring samples through the use of corpora.

Keywords: phrasal verbs; corpus-based data; concordance lines; grammatical patterns; collocations 


\section{A corpus-based study of phrasal verbs: CARRY OUT, FIND OUT, and POINT OUT}

\section{Introduction}

Phrasal verbs (PVs) in English language are notoriously challenging for many learners of English as a foreign language (EFL) and English as a second language (ESL). They are not only abundant, but also semantically and syntactically complex. In terms of its common occurrences, based on the 100-million-word British National Corpus (BNC), Gardner and Davies (2007) pointed out that readers can find one PV in every 192 words of English, or roughly two per page of a written text. Moreover, the unpredictable combinations of verbs and particles, as well as the complexity of syntactic and semantic features of PVs (Side, 1990; Liao \& Fukuya, 2004; Liu, 2011) make PVs difficult for learners to understand and result in the avoidance of PVs. More research on PVs in diverse aspects could benefit learners of English language as they can understand more about PVs and gain more confidence when using them.

The aim of this research is to investigate grammatical patterns and collocations of three target PVs, i.e., carry out, find out, and point out. The concordance lines, or the samples presented with the search word in the middle of the lines with seven or eight words shown at either side, were recruited from the Corpus of Contemporary American English (COCA). In addition, the Oxford Advance Learner's Dictionary (OALD, 2010) was used as the reference source of information about grammatical patterns and collocations after the data collection and data analysis from COCA were completed.

\section{Literature Review}

\subsection{Corpus Linguistics}

There has been growing interest in the field of corpus linguistics in the past few decades. In corpus linguistics, a corpus (or corpora in the plural form) can be referred to as a principled collection of electronic texts usually stored on a computer available for qualitative and quantitative analysis (O' Keffe, McCarthy, \& Carter, 2007). Conrad (1999) discussed three distinct characteristics of corpus-based research.

Firstly, corpus-based research uses a principled collection of naturally-occurring texts. Naturally-occurring texts do not only refer to written texts, but also include spoken ones or a mix of both types. Corpora can be gathered and built from various sources, such as academic textbooks, newspapers, magazines, students' work, conference, classrooms, political speeches, TV series, the Internet, etc. Aside from sources of texts, to serve the principled collection purpose, the size and design of the corpus should be emphasized to ensure that the corpus contains good representative samples and proper varieties of texts. Reppen (2010) suggested that there is no specific size of a corpus that fits all studies. Studies of common grammatical features can rely on small-size corpora, while far bigger corpora are required for the research of less common features.

Secondly, since corpora comprise a great deal of texts and they are stored on a computer, the corpus-based studies can benefit from the use of computers and specially designed software to analyze the samples from corpora. Many aspects or complex patterns of language can be discovered by using corpus software together with a researcher's judgment. Thirdly, corpus-based studies include both quantitative and qualitative analysis. Quantitative analysis helps to obtain the results, such as the number of occurrences, and the major patterns in any corpora being studied. On the other hand, the function of language or how a word or phrase is used in various situations can be achieved through qualitative analysis. 


\subsection{Definition of Phrasal Verb}

Researchers and linguists have proposed various definitions of PVs (Celce-Murcia \& Larsen-Freeman, 1999; Darwin \& Gray, 1999; Gardner \& Davies, 2007; Quirk, Greenbaum, Leech, \& Svartvik, 1985). A PV, as defined by Darwin \& Gray (1999), is generally "a verb + particle combination that functions as a single verb, both parts giving up meaning in order to form a new lexical item” (p. 65). Quirk et al. (1985) described a PV as a multi-word verb that possesses either syntactic or semantic features to some degree and behaves as a single grammatical form.

As far as dictionaries are concerned, a PV, according to Oxford Advanced Learner's Dictionary (2010), is “a verb combined with an adverb or a preposition, or sometimes both, to give a new meaning" (p. 1101). Longman Dictionary of Contemporary English (2005) provides the meaning of a phrasal verb as "a group of words that is used like a verb and consists of a verb with an adverb or preposition after it" (p. 1232). Similarly, Macmillan English Dictionary for Advanced Learners (2002) defines it as "a combination of words that is used like a verb and consists of a verb and an adverb or preposition" (p. 1062). Although the definitions given by different sources differ to some degree, the variations are rather slight from a language learner's point of view.

\subsection{Syntactic Features of Phrasal Verbs}

A PV is syntactically a lexical verb followed by morphologically invariable particle and functions as a single verb (Quirk et al, 1985). The particles can be prepositions (such as against, among, as, at, beside, for, from, into, on top), spatial adverbs (such as aback, ahead, apart, aside, astray, away, back), or prepositional adverbs (such as about, above, across, after, down, in, off, out). Celce-Murcia and Larsen-Freeman (1999) offered broadly three major syntactic features of PVs as follows:

\subsubsection{Transitive and Intransitive Phrasal Verbs}

Like single-unit verbs, PVs can be either transitive or intransitive. Transitive PVs can take an object, e.g. Mercy filled in the application form. The PV filled in precedes the object the application form. On the other hand, some PVs are intransitive as they do not require an object, e.g. the plane took off. In this case, the PV took off does not take an object. Intransitive verbs, as suggested by Eastwood (1994), are usually used to show that someone is doing something.

\subsubsection{Phrasal Verbs that Require Prepositions}

A number of PVs prefer a specific preposition; therefore, these PVs and preposition must be learned as one unit. Quirk et al. (1985) called them phrasal-prepositional verbs and suggested that "a common sign of idiomatic status ... is the existence of a one-word paraphrase" (p. 1160). Some examples are put up with 'tolerate', look up to 'admire', and do away with 'abolish'. The prepositions with, to, and with were added to put up, look up, and do away, respectively, resulting in more complex PVs.

\subsubsection{The Separability of Phrasal Verbs}

A distinct syntactic feature of transitive PVs is that sometimes the direct object can be inserted between the lexical verb and the particle (separable PVs), but at other times it cannot (inseparable PVs). It is worth noting that when the direct object is a pronoun, the separation is mandatory.

In summary, the grammatical pattern of PVs can be summarized in the formula: "verb \pm direct object \pm adverb \pm preposition" (Quirk et al., 1985, p. 1161). Table 1 illustrates and exemplifies various grammatical patterns of PVs. 


\section{Table 1}

Patterns of Phrasal Verbs

\begin{tabular}{|c|c|c|c|c|c|c|}
\hline & \multirow[b]{2}{*}{ Pattern } & \multirow[b]{2}{*}{$\begin{array}{l}\text { Lexical } \\
\text { Verb }\end{array}$} & \multirow[b]{2}{*}{ Direct Object } & \multicolumn{2}{|c|}{ Particles } & \multirow[b]{2}{*}{$\begin{array}{c}\text { Prepositional } \\
\text { Object (prep. obj) }\end{array}$} \\
\hline & & & & $\begin{array}{c}\text { Adverb } \\
\text { (spatial or } \\
\text { prepositional) }\end{array}$ & Preposition & \\
\hline 1 & $\begin{array}{ll}\text { Phrasal } & \text { verb } \\
\text { (Intransitive) } & \end{array}$ & show & - & up & - & - \\
\hline 2 & $\begin{array}{l}\text { Phrasal verb } \\
\text { (Transitive) } \\
\text { - Separable (1) }\end{array}$ & write & the information & down & - & - \\
\hline & - Separable (2) & write & - & down & - & the information \\
\hline & - Inseparable & call & - & on & - & an old friend \\
\hline 3 & $\begin{array}{l}\text { Phrasal-prepositional } \\
\text { verb (Intransitive) }\end{array}$ & get & - & along & with & $\begin{array}{c}\text { Tony } \\
\text { (prep.obj) }\end{array}$ \\
\hline 4 & $\begin{array}{l}\text { Phrasal-prepositional } \\
\text { verb (Transitive) }\end{array}$ & put & their success & down & to & $\begin{array}{l}\text { team spirit (prep. } \\
\text { obj) }\end{array}$ \\
\hline
\end{tabular}

\subsection{Semantic Features of Phrasal Verbs}

Quirk et al. (1985) pointed out that the meaning of PVs can often be explained with one-word verbs. They divided PVs into three main types including (a) "free, non-idiomatic construction", where the individual meanings of the component are obvious, (b) "semi-idiomatic construction", where the verb keeps its meaning, and the particle provides aspectual meaning, and (c) "highly-idiomatic construction", where the combination of a verb and the particle gives special meanings.

\subsection{Collocations}

Collocation, as defined by Oxford Advanced Learner's Dictionary (2010), is "a combination of words in a language, that happens very often and more frequently than would happen by chance" (p. 279). Benson, Benson, and Ilson (2010) suggested that collocations, also called recurrent combinations or fixed combinations, are phrases and constructions that are fixed, identifiable, and non-idiomatic. They can be divided into two main groups including grammatical collocations and lexical collocations. While grammatical collocations are composed of a content word (nouns, adjectives, verbs) and a function word that is normally a preposition, lexical collocations are made up of nouns, adjectives, verbs, and adverbs. Table 2 and Table 3 present examples of grammatical and lexical collocations.

\section{Table 2}

Examples of Grammatical Collocations

\begin{tabular}{l|l}
\hline 1. Noun $(\mathrm{N})+$ Preposition (Prep) & an act of, a decrease in \\
\hline 2. Prep $+\mathrm{N}$ & by origin, in advance \\
\hline 3. Adjective (Adj) + Prep & aware of, fond of \\
\hline 4. Verb $(\mathrm{V})+$ Prep & rely on, escape from \\
\hline
\end{tabular}


Table 3

Examples of Lexical Collocations

\begin{tabular}{l|l}
\hline $1 . \mathrm{V}+\mathrm{N}$ & compose music, reject an appeal \\
\hline 2. $\mathrm{V}+\mathrm{N}$. clause beginning with that & I hope that she will be happy. \\
\hline $3 . \mathrm{V}+$ wh-word & I know what he wants. \\
\hline 4. Adj + N & strong tea, heavy rain \\
\hline $5 . \mathrm{N} /$ Pronoun (Pron) $+\mathrm{V}$ & water boils, the sun shines \\
\hline 6. Quantifier $+\mathrm{N}$ & a flock of birds, a piece of advice \\
\hline 7. Adverb (Adv) + Adj & bitterly cold, deeply grateful \\
\hline 8. V + Adv & walk quickly, identify accurately \\
\hline $9 . \mathrm{Adv}+\mathrm{V}$ & seriously harmful, strongly recommend \\
\hline
\end{tabular}

\subsection{Relevant Research}

Several studies (Liao and Fukuya, 2004; Gardner and Davies, 2007; Yasuda, 2010; Liu, 2011) have been carried out to investigate phrasal verbs in various aspects, such as the combination of phrasal verbs, the most frequently used phrasal verbs, and the avoidance of learners towards the use of phrasal verbs.

Gardner and Davies (2007) conducted corpus-based research on English phrasal verbs based on the 100-million-word British National Corpus (BNC) with an aim to determine the most frequent adverbial particles and lexical verbs used in phrasal verbs construction, to explore how these lexical verbs interact with various adverbial particles, to provide a list of the most frequent phrasal verbs based on overall frequency and coverage, and to approximate the number of word senses relating to each of the most frequent phrasal verbs. Their study was exploratory and informative in nature. The data gathered from BNC were divided into several sets of multi-word chunks such as two-, three-, four-, until seven-word chunks. Next, they were processed through the software to identify and report the instances where the combinations of lexical verbs and adverbial particles occur. The outcomes were then lemmatized in order to count all the possibilities of verb forms together. The outcomes from the data collection process were semantically analyzed. The results from this study showed the eight most frequent adverbial particles (i.e., out, up, on, back, down, in, off, and over) and 20 most frequent lexical verbs (go, come, take, get, set, carry, turn, bring, look, put, pick, make, point, sit, find, give, work break, hold, and move). The combination of these lexical verbs and adverbial particles accounted for 53.7 percent of all the phrasal verbs in BNC. The researchers also came up with the top 100 phrasal verb lemmas in BNC (such as go on, carry out, set up, pick up, go back, etc.), which make up approximately half of all the phrasal verbs in $\mathrm{BNC}$, and these 100 phrasal verbs have roughly 559 various meanings, or on average 5.6 meanings per phrasal verb. The researchers finally maintained that these findings can be applied in pedagogy and future research in order to improve the instruction of English phrasal verbs.

Liu (2011) provided three limitations of Gardner and Davies' (2007) work, i.e., (1) a list of 100 high-frequency phrasal verbs derived from only the top 20 lexical verbs, (2) since the work was conducted using the data from BNC, which is a source for British English only, there might be questions as to whether the results are also true for other major English varieties, and (3) the study did not explore the phrasal verbs in diverse registers. Liu (2011) conducted multi-corpus research aiming to offer a comparative examination of the most frequently used phrasal verbs between American and British English and an investigation of their usage across registers in American English. The primary corpus used was the Corpus of Contemporary American English (COCA), and BNC was employed as a secondary corpus for comparison purposes. The 40-million-word 
Kiativutikul, C. \& Phoocharoensil, S.

Longman Spoken and Written English (LSWE) corpus was also used indirectly for cross-corpora comparison. The researcher identified the frequency and usage patterns of the high frequency phrasal verbs from COCA and BNC, and then analyzed the outcomes statistically. The findings revealed a list of 150 common phrasal verbs in American and British English, which include 100 phrasal verbs from Gardner and Davies' (2007) study, and 50 additional items. The research also provided a cross-register table of those phrasal verbs that indicated which register each phrasal verb tends to occur. Furthermore, the researcher pointed out that the difference between two main corpora could result from the difference in time period of BNC covering the 1980s to 1993 and COCA ranging from 1990 to 2012. The other reason is the preference in the use of around and round in phrasal verbs between American and British English varieties: Americans favor around while British prefer round. Due to this and the fact that certain pairs of lexical verbs + around/round are synonymous, the researcher grouped them together, resulting in look around with look round, turn around with turn round, come around with come round, and go around with go round. Finally, the researcher offered implications for English learners, teachers, and future researchers. English learners and teachers can adopt the list of the 150 most common phrasal verbs for their learning and instructing purposes. Future research can be carried out to examine the different meanings of phrasal verbs across registers.

Liao and Fukuya (2004) carried out research with 85 students to investigate their avoidance of English phrasal verbs. Of the 85 students, 15 were native speaker undergraduate students, 30 were advanced level Chinese graduate students, and the remaining 40 were Chinese intermediate learners of English. Three kinds of tests including multiple-choice, translation, and recall were employed in the study to test students' knowledge of the lexical and figurative meanings of phrasal verbs. With the Chinese students separated into six groups, each group took one of the three tests. On the other hand, the native speaker students were assigned to take the multiple-choice test. The results showed that the intermediate learners whose L1 lacks phrasal verbs had a tendency to avoid phrasal verbs and preferred using one-word verbs, while the advanced learners did not. However, the advanced and intermediate students tended to produce more literal phrasal verbs than figurative ones as shown in the translation task. The researcher concluded that the avoidance of phrasal verbs was the result of learners' inter-language development rather than L1-L2 differences or similarities. Furthermore, the avoidance of phrasal verbs could be attributed to their semantic and syntactic difficulties. The authors also suggested that the exposure of learners to the $\mathrm{L} 2$ environment might help reduce the avoidance of phrasal verbs phenomenon.

Yasuda (2010), realizing that phrasal verbs is one of the obstacles for English language students despite the high frequency of their occurrence, performed a research study to investigate whether increasing the awareness of orientational metaphors of particles through the cognitive linguistic approach can help Japanese EFL students in phrasal verbs acquisition. Twenty-one phrasal verbs with the adverbial particles up, down, into, out, and off, namely break down, burst into, call off, calm down, dry up, enter into, figure out, get off, keep off, knock down, leave out, make out, open up, pay off, rule out, run into, show up, take off, turn down, turn into, and use up, were examined in this study. According to the researcher, the five particles could create orientational metaphors, i.e., (1) the particle up for more visible, accessible, and completion, (2) the particle down for lowering, decreasing, defeating, and suppressing, (3) the particle into for changing, (4) the particle out for removing, excluding, searching, and finding, and (5) the particle off for departure, separation, stopping, cancelling, prevention, and protection. The participants were 115 freshmen Japanese students enrolled in the English language program at the School of Liberal Arts in a private university in Tokyo, Japan. They had studied English as a foreign language for at least six years in their formal education and their average score on the Test of English as a Foreign Language (TOEFL) was 450. The students were divided into two groups: a control group comprising 56 students and an experimental group made up of 59 students. The control group received the traditional teaching method, i.e., rote learning. A teacher provided the meaning of phrasal verbs and asked students to memorize them. On the other hand, the experimental group was taught through the cognitive approach. The phrasal verbs were explained based on the orientational metaphors to which each particle contributed. After instruction, both groups of students took the phrasal verb test containing 15 taught phrasal verbs and the other 15 untaught items. The results showed that the performance of both groups, on average, was quite high and there was no significant 
difference between them for the phrasal verbs they were taught before taking the test. However, for the unexposed category of phrasal verbs, the experimental group was able to outperform the control group since the experimental group was more likely to derive the meaning of phrasal verbs from metaphorical thought. The researcher concluded that the cognitive linguistic approach of enhancing the awareness of orientational metaphors could be a supplementary or facilitating strategy for students learning phrasal verbs, apart from the traditional approach of memorization.

Although many studies have examined the complications of phrasal verbs in various angles such as the combination of structures, semantic features, frequently used phrasal verbs, and the avoidance of phrasal verbs among ESL and EFL learners, very little research has been conducted to investigate the grammatical patterns and the collocations of particular phrasal verbs. The purpose of this study is to explore the grammatical patterns and collocations of three phrasal verbs, which are carry out, find out, and point out, based on COCA. Apart from the two main objectives of this study, the findings might show that a phrasal verb could be genre-specific. It would, therefore, raise learners' awareness towards the appropriate use of phrasal verbs in various registers or modes of communication. Finally, English language learners can adapt the methodology of this study for future research on other phrasal verbs in the same or different linguistic aspects. This would encourage students to learn English language independently.

\section{Methodology}

\subsection{Target Phrasal Verbs}

Three phrasal verbs: carry out, find out, and point out were selected as the focus of this study because of the following reasons:

3.1.1 The adverbial particle out is among the top three most prolific adverbial particles in forming PVs (Gardner \& Davies, 2007; and Zarifi \& Mukundan, 2012);

3.1.2 The lexical verbs carry, find, and point are the top 20 lexical verb lemmas functioning in PV forms (Gardner \& Davies, 2007);

3.1.3 The PVs carry out, find out, and point out are the top 50 phrasal verb lemmas in BNC (Gardner \& Davies, 2007), in COCA (Liu, 2011), and in Malaysian ESL textbooks corpus (Zarifi \& Mukundan, 2012).

\subsection{Materials}

The corpus used for this study was the Corpus of Contemporary American English (COCA), which was created by Mark Davies, a professor of linguistics at Brigham Young University in Utah, USA. It contains 450 million words collected from 1990 to 2012, and is composed of diverse text types, i.e., spoken (Spok), fiction (Fic), magazine (Mag), newspaper (News), and academic (Acad). Researchers and learners can use the concordance lines (or samples) recruited from COCA to review the patterns of node words, as well as to analyze and make comparisons across genres or over time. In addition, Oxford Advanced Learner's Dictionary (2010) was used as the main reference for the information about the target PVs.

\subsection{Procedures}

This study is exploratory and corpus-based research in which the concordance lines were sampled randomly from COCA. With regard to data collection, the researcher used the search features of the COCA online program at http://corpus.byu.edu provided by Brigham Young University to retrieve 500 concordance lines for each target PV. The criteria for the three lexical verbs and adverbial particle out were set to obtain the desired samples. 
Kiativutikul, C. \& Phoocharoensil, S.

\subsection{Data Analysis}

To perform data analysis of the 500 concordance lines for each target PV lemma: carry out, find out, and point out, the researcher made use of an Excel spreadsheet. The steps were as follows:

3.4.1 The 500 concordance lines of each target PV, which were the outcomes of the query, were copied and placed on the Excel spreadsheet.

3.4.2 The concordance lines were sorted in alphabetical order of the lemma and they were then ready for analysis.

3.4.3 The researcher investigated the sorted concordance lines for the grammatical patterns and collocates of each PV.

3.4.4 The results from the previous step were summarized and compared with the information given by Oxford Advanced Learner's Dictionary (2010).

\section{Results}

\subsection{Distribution of PVs across Registers}

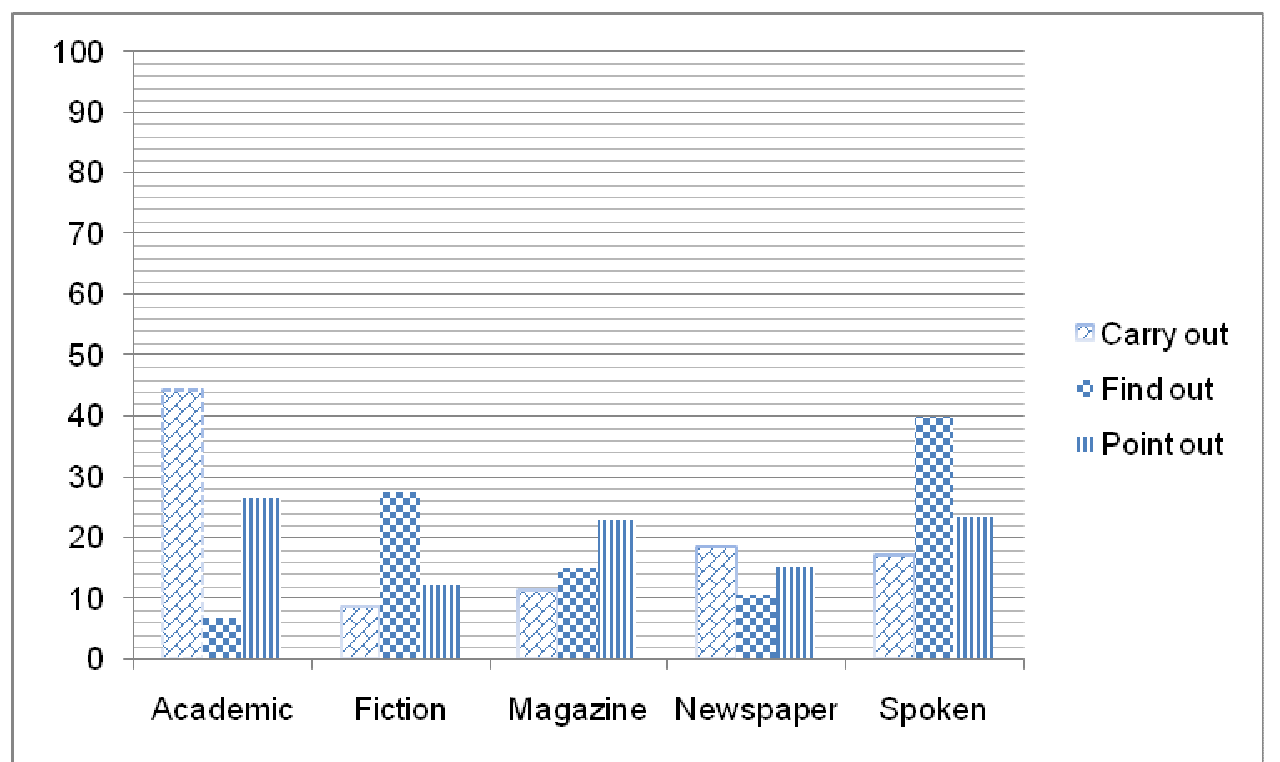

Figure 1. Percentage distribution of carry out, find out, and point out across registers in COCA

As illustrated in Figure 1, the word carry out was used strikingly much more often in the academic genre as compared to find out, which appeared very frequently in the spoken one. In addition, the bar graph reveals that carry out and point out seem to occur in a similar manner across different registers.

\subsection{Grammatical Patterns}

Tables 4 to 6 present the possible grammatical patterns of each phrasal verb, as compared to those shown in OALD (2010), and their frequency. The samples of concordance lines are also displayed after each table. The grammatical patterns of carry out listed in Table 4 are generally in accordance with those shown in OALD (2010). Moreover, the results reveal the preference of using carry out in an active voice (58.80\%) to using it in a passive voice $(41.20 \%)$. 


\section{Table 4}

Grammatical Patterns of Carry Out and Their Frequency

\begin{tabular}{|c|c|c|c|c|}
\hline \multirow[t]{2}{*}{ Phrasal Verb } & \multirow[t]{2}{*}{ OALD (2010) } & \multirow[t]{2}{*}{ Present Study } & \multicolumn{2}{|c|}{ Frequency } \\
\hline & & & Token & Percentage \\
\hline \multirow[t]{2}{*}{ carry out } & $\begin{array}{l}\text { carry out }+ \text { something } \\
(\mathrm{sth})\end{array}$ & $\begin{array}{l}\text { 1. carry/carries/carried/be } \\
\text { carrying out }+\mathrm{sth}\end{array}$ & 294 & $58.80 \%$ \\
\hline & $\begin{array}{l}\text { to be carried out + } \\
\text { preposition (prep) }\end{array}$ & 2. to be carried out + (prep) & 206 & $41.20 \%$ \\
\hline \multicolumn{3}{|l|}{ Total } & 500 & $100.00 \%$ \\
\hline
\end{tabular}

From the corpus data below, the samples of possible grammatical patterns of carry out are as follows:

a. carry/carries/carried/to be carrying out + something (sth)

b. to be carried out + preposition (prep) as in lines 1 to 11

as in lines 12 to 21

Corpus data:

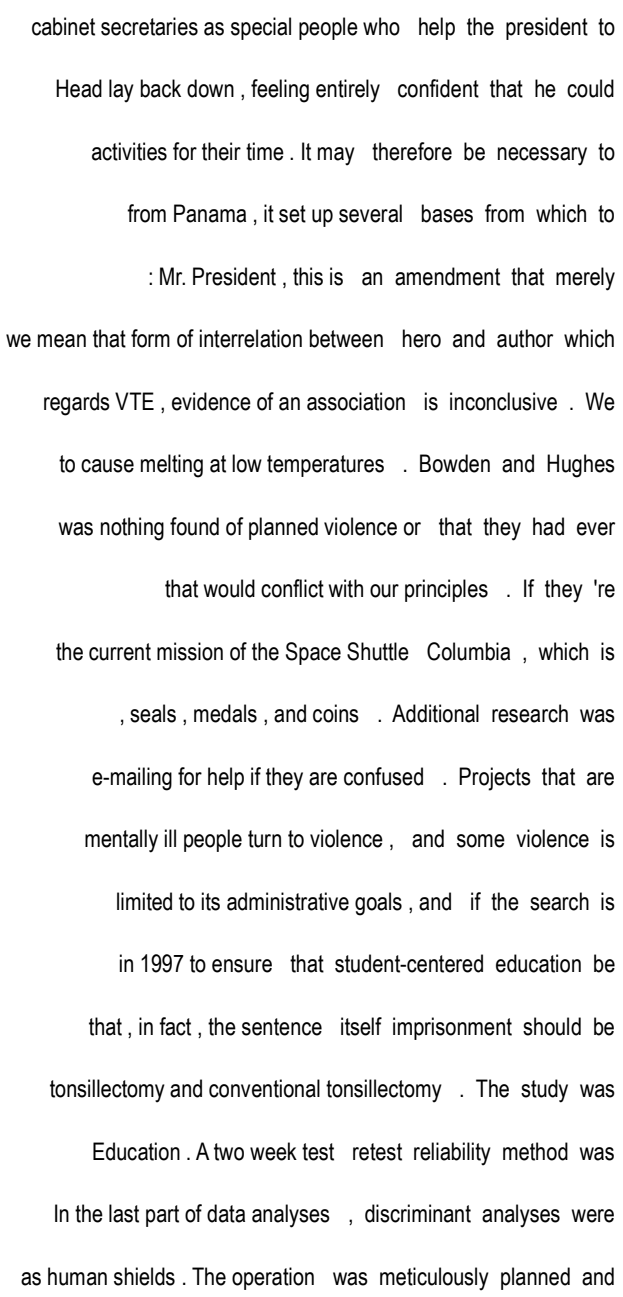

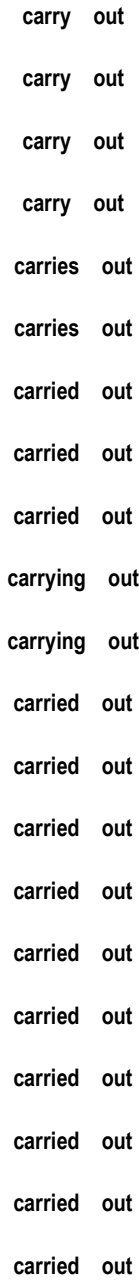

his many tasks. The lesson began with the students '

the moral mission of the coming day. He meant to

a further studies to investigate the activities competing counter-drug operations. The only one in South America is the intent that Congress has shown on many occasions to the task of creating a whole hero as a defined personality 
Kiativutikul, C. \& Phoocharoensil, S.

Table 5

Grammatical Patterns of Find Out and their Frequency

\begin{tabular}{|c|c|c|c|c|}
\hline \multirow[t]{2}{*}{ Phrasal Verb } & \multirow[t]{2}{*}{ OALD (2010) } & \multirow[t]{2}{*}{ Present Study } & \multicolumn{2}{|c|}{ Frequency } \\
\hline & & & Token & Percentage \\
\hline \multirow[t]{8}{*}{ find out } & $\begin{array}{l}\text { find out }+ \text { wh-word } \\
\text { clause }\end{array}$ & $\begin{array}{l}\text { 1. find/finds/found out }+ \\
\text { wh-word clause }\end{array}$ & 191 & $49.48 \%$ \\
\hline & find out + that clause & $\begin{array}{l}\text { 2. find/finds/found/be finding } \\
\text { out }+ \text { (that) clause }\end{array}$ & 95 & $24.61 \%$ \\
\hline & $\begin{array}{l}\text { find out }+(\text { about }+ \\
\mathrm{sth} / \mathrm{sb})\end{array}$ & $\begin{array}{l}\text { 3. find/finds/found out }+ \text { (about }+ \\
\text { sth/sb) }\end{array}$ & 53 & $13.73 \%$ \\
\hline & $\begin{array}{l}\text { find out }+ \text { sth }+ \\
\text { (about sth/sb) }\end{array}$ & $\begin{array}{l}\text { 4. find/finds/found out }+\mathrm{sth}+ \\
\text { (about } \mathrm{sth} / \mathrm{sb} \text { ) }\end{array}$ & 34 & $8.81 \%$ \\
\hline & - & $\begin{array}{l}\text { 5. find/finds/found out }+ \text { from }+ \\
\mathrm{sb} / \mathrm{sth}\end{array}$ & 8 & $2.07 \%$ \\
\hline & - & 6. find out + for sth & 3 & $0.78 \%$ \\
\hline & - & 7. find/finds/found out + unless & 1 & $0.26 \%$ \\
\hline & - & 8. to be found out & 1 & $0.26 \%$ \\
\hline \multicolumn{3}{|l|}{ Total } & 386 & $100.00 \%$ \\
\hline
\end{tabular}

As shown in Table 5, the majority of the possible patterns of find out are those presented in the OALD (2010). These patterns account for approximately 97 percent of the total concordance lines being summarized. The remaining grammatical patterns, accounting for 3 percent, are not shown in OALD (2010). In addition, the results reveal that the occurrences of the phrasal verb find out tend to be in an active voice rather than in a passive voice.

From the corpus data below, possible grammatical patterns of find out are as follows:
a. find/finds/found out + wh-word clause
b. find/finds/found/be finding out + that clause
c. find/finds/found out + (about $+\mathrm{sth} / \mathrm{sb}$ )
d. find/finds/found out $+\mathrm{sth}+($ about $\mathrm{sth} / \mathrm{sb}$ )
e. find/finds/found out + unless
f. find/finds/found out + from + somebody $(\mathrm{sb})$
g. find out + for + sth
h. to be found out

as in lines 22 to 36

as in lines 37 to 40

as in lines 41,42

as in lines 43 to 46

as in line 47

as in lines 48, 49

as in lines 50,51

as in line 52

It is to be noted that the clause marker that is sometimes omitted as in lines 39 and 40. 
Corpus data:

\begin{tabular}{|c|c|c|c|c|}
\hline 22 & lunch hour is up, we walk back over to & find & out & how many orders have come in. If a lot of orders \\
\hline 23 & their movie, " Photo Finish , " and to & find & out & how they worked a rubber duck into the film, visit our \\
\hline 24 & For the basic research that would enable us to & find & out & how to control these cells, how to get them to differentiate \\
\hline 25 & outset of todays hearing that the panel is determined to & find & out & what caused the collapse. PHIL-ANGELIDES-Ch : To conduct a \\
\hline 26 & even the police fear to tread. She went to & find & out & what happened to the love of her life. \# Donato died \\
\hline 27 & job. When we return, we 're going to & find & out & what it really takes to be a police officer from two of \\
\hline 28 & Friday, we 've just been kind of waiting to & find & out & when we were going to be evacuated or how we were going \\
\hline 29 & not do that? Then the American people could really & find & out & whether the candidates understand the issues, whether the \\
\hline 30 & free labor here on the side and you get to & find & out & whether you enjoy making beds, cleaning toilets, making scones \\
\hline 31 & such a test for the puppies that it breeds to & find & out & which ones would make good guide dogs. Let 's find out \\
\hline 32 & papers in a shiny waterproof bag . " Now I & find & out & who gets seasick. You want a life jacket ? You 're \\
\hline 33 & in Wexford, Pa." It inspired me to & find & out & who I really am and where my identity really is." \\
\hline 34 & and Christel Neukirche would like to see their file to & find & out & whose information sent Hans, a truck driver, to jail and \\
\hline 35 & to the next eager young person . Eventually they 'II & find & out & why they die. Offer enough money, people will do what \\
\hline 36 & , it is often extraordinarily difficult for donors to & find & out & where their own money has gone or what it has achieved. 5 \\
\hline 37 & It 's basically kind of -- you know , to & find & out & that someone close to you would do something like this, it \\
\hline 38 & having to experience that again. And we come to & find & out & that they were doing the exact things they were criticizing \\
\hline 39 & ,'Mr. Egan said. " Subsequently, you & find & out & it will cost you another $\$ 5,000$ a year to maintain it. \\
\hline 40 & dorms. I was 19 years old .1 just & found & out & I was pregnant. My body did n't go through the normal \\
\hline 41 & was really serious about singing, he would have to & find & out & about Louis Armstrong, a young trumpet player and singer in \\
\hline 42 & is almost always a dangerous combination . Eduard never & found & out & about my extracurricular activities, but we did find ourselves \\
\hline 43 & Buffett? Call him up, meet with him , & find & out & his secrets. Readers will love it. \# Me : Oh \\
\hline 44 & mother who 's always been very cold and distant & finds & out & these incredible secrets about her parents. And I think a lot \\
\hline 45 & my father. When my father passed away , I & found & out & several things about him. Among them that he had been a \\
\hline 46 & , " I said with exaggerated patience , " to & find & out & something about your people . Why, for instance, they delight \\
\hline 47 & \# The offense is fine. ' You do n't & find & out & unless you play good people. What good is false confidence? \\
\hline 48 & I arrive at an Amish community or function , I & find & out & from a knowledgable source if this is a liberal or conservative \\
\hline 49 & was tell me to my face . I have to & find & out & from Nana. In a phone call. " \# Frances could \\
\hline 50 & were made for some good purpose , which we must & find & out & for ourselves. When the doctor does not know what medicine to \\
\hline 51 & Let them reach their own limits . Let them & find & out & for themselves. That 's the purpose of life -- to grow \\
\hline 52 & , intense and sharp: " It can not be & found & out & " // In the first moments of cold, with the \\
\hline
\end{tabular}


Kiativutikul, C. \& Phoocharoensil, S.

Table 6

Grammatical Patterns of Point Out and Their Frequency

\begin{tabular}{|c|c|c|c|c|}
\hline \multirow[t]{2}{*}{ Phrasal Verb } & \multirow[t]{2}{*}{ OALD (2010) } & \multirow[t]{2}{*}{ Present Study } & \multicolumn{2}{|c|}{ Frequency } \\
\hline & & & Lines & Percentage \\
\hline \multirow[t]{6}{*}{ point out } & $\begin{array}{l}\text { point out }+(\text { to } \mathrm{sb})+ \\
\text { that clause }\end{array}$ & $\begin{array}{l}\text { 1. point/points/pointed out }+ \text { (to } \\
\mathrm{sb})+ \text { that } \text { clause }\end{array}$ & 254 & $53.92 \%$ \\
\hline & point out + sth & $\begin{array}{l}\text { 2. point/points/pointed out }+\mathrm{sth}+ \\
\text { (about) }\end{array}$ & 80 & $16.99 \%$ \\
\hline & - & $\begin{array}{l}\text { 3. as }+\mathrm{sb}+\text { point/points/pointed } \\
\text { out }+ \text { clause } \\
\text { 4. sentence component, as }+\mathrm{sb}+ \\
\text { points/pointed out, sentence } \\
\text { component } \\
\text { 5. clause, as }+\mathrm{sb}+\text { points/pointed } \\
\text { out }\end{array}$ & $\begin{array}{l}52 \\
13\end{array}$ & $\begin{array}{l}11.04 \% \\
2.76 \% \\
0.64 \%\end{array}$ \\
\hline & $\begin{array}{l}\text { "speech," + sb + } \\
\text { pointed out. }\end{array}$ & $\begin{array}{l}\text { 6. "speech," + sb + } \\
\text { point/points/pointed out } \\
\text { 7. "sentence component," sb + } \\
\text { point/points/pointed out, } \\
\text { "sentence component" } \\
\text { 8. "speech," points out + subject } \\
\text { 9. sb + point/points/pointed out, } \\
\text { "speech" }\end{array}$ & $\begin{array}{l}34 \\
11\end{array}$ & $\begin{array}{l}7.22 \% \\
2.34 \%\end{array}$ \\
\hline & - & $\begin{array}{l}\text { 10. point/points/pointed out }+ \text { (to } \\
\mathrm{sb})+ \text { wh-word clause }\end{array}$ & 16 & $3.40 \%$ \\
\hline & - & 11. to be pointed out $+(\mathrm{by}+\mathrm{sb})$ & 5 & $1.06 \%$ \\
\hline \multicolumn{2}{|l|}{ Total } & & 471 & $100.00 \%$ \\
\hline
\end{tabular}

Moving on to Table 6, Pattern 1 "point/points/pointed out + (to sb) + that clause" is the major structure accounting for slightly above half the total of concordance lines, followed by Pattern 2 "point/points/pointed out + sth + (about)", which is around 17 percent. Patterns 3, 4, and 5, in general, deal with a fragment "as + sb + point/points/pointed out" and a clause. The fragment "as $+\mathrm{sb}+$ point/points/pointed out" can precede, follow, and appear between the two broken parts of a clause. In this group, Pattern 3 scores the highest in frequency (11.04\%). Patterns 6, 7, 8, and 9 involve direct speech ("speech") and the information about who the speaker is $(\mathrm{sb}+$ point/points/pointed out, or points out $+\mathrm{sb})$. Similar to Patterns 3, 4, and 5, the information about who is speaking in Patterns 6, 7, and 9 can precede, follow, and appear between the two broken pieces of direct speech. However, in Pattern 8, the information about who is speaking is put after a direct speech. From this subcategory, Pattern 6 occurs with the highest frequency. 
From the corpus data below, possible grammatical patterns of point out are as follows:
a. point/points/pointed out + (to $s b)+$ that
as in lines 53 to 56
b. point/points/pointed out $+\mathrm{sth}+$ (about)
as in lines 57,58
c. as $+\mathrm{sb}+$ point/points/pointed out, + clause
as in lines 59, 60
d. sentence component, as $+\mathrm{sb}+$ points/pointed out, sentence component
as in lines 61, 62
e. clause, $a s+s b+$ point/points/pointed out
as in line 63
f. "speech," $+\mathrm{sb}+$ point/points/pointed out
as in line 64,65
g. "sentence component," sb + point/points/pointed out, "sentence component"
as in lines 66,67
h. "speech," points out + subject
as in line 68
i. $s b+$ point/points/pointed out, "speech"
as in line 69
j. point/points/pointed out + wh-clause
as in lines 70,71
k. to be pointed out $+($ by $+s b)$
as in lines 72,73

Corpus data:

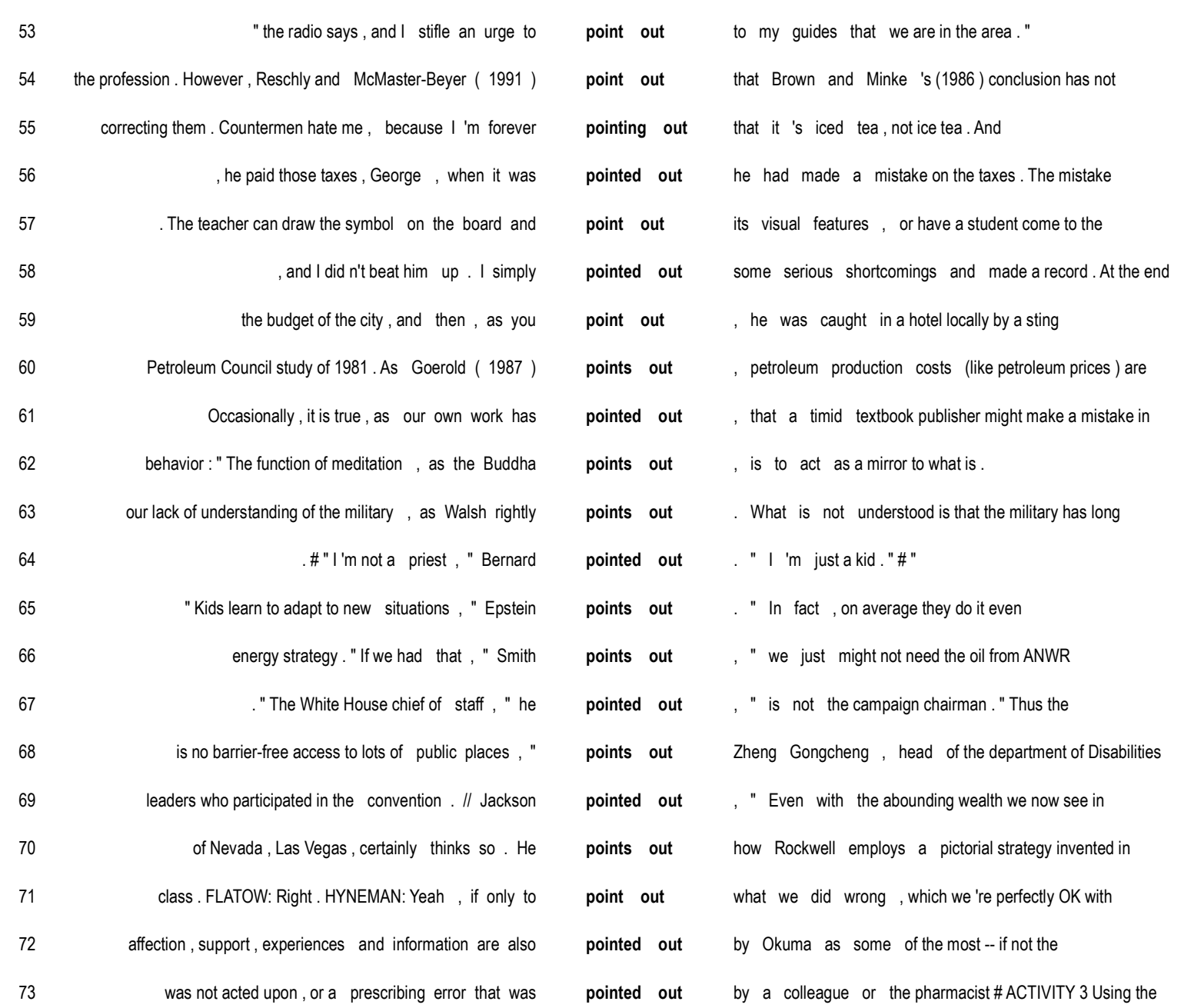

In summary, the grammatical patterns revealed from the present study are generally in accordance with those presented in OALD (2010). However, there are a few differences between both of them, which are highlighted in grey. This might be due to the fact that the dictionary has limited space, and it is probably not the main purpose of a dictionary to illustrate all the possible patterns. 
Kiativutikul, C. \& Phoocharoensil, S.

\subsection{Collocations}

The researcher summarizes the frequency of collocates of the target PVs in Table 7. Their main collocates differ in types where 1) prepositions and object nouns are the first three common collocates of carry out, 2) subject nouns/pronouns, wh-words, and that clause are collocates of find out, and 3) that clause and subject nouns/pronouns are collocate with point out with the highest and second-highest frequency respectively. It is also worth noticing that adverbs do not co-occur frequently with these PVs. Examples of collocates of carry out, find out, and point out from this study are given in Table 8.

Table 7

Summary of Different Types of Collocates That Co-Occur With the Target Phrasal Verbs

\begin{tabular}{|c|c|c|c|}
\hline \multirow{2}{*}{ Frequency of the collocation } & \multicolumn{3}{|c|}{ Phrasal verb (PV) } \\
\hline & Carry out & Find out & Point out \\
\hline \multicolumn{4}{|l|}{ Grammatical collocation } \\
\hline 1. Phrasal verb $(\mathrm{PV})+$ preposition & 137 & 73 & 38 \\
\hline \multicolumn{4}{|l|}{ Lexical collocation } \\
\hline 1. $\mathrm{PV}+$ noun & 111 & 15 & 26 \\
\hline 2. noun/pronoun $+\mathrm{PV}$ & 50 & 223 & 187 \\
\hline 3. $\mathrm{PV}+$ adverb & 14 & 17 & 11 \\
\hline 4. adverb + PV & 4 & 11 & 14 \\
\hline 5. $\mathrm{PV}+$ that clause & - & 95 & 237 \\
\hline 6. $\mathrm{PV}+$ wh-words & 5 & 191 & 16 \\
\hline
\end{tabular}

\section{Table 8}

Examples of Collocates That Co-Occur With the Target Phrasal Verbs

\begin{tabular}{|c|c|c|c|}
\hline \multirow{2}{*}{ Example of collocates } & \multicolumn{3}{|c|}{ Phrasal verb (PV) } \\
\hline & Carry out & Find out & Point out \\
\hline \multicolumn{4}{|l|}{ Grammatical collocation } \\
\hline 1. Phrasal verb $(\mathrm{PV})+$ preposition & by, in, on, with & about, from & to, in, by \\
\hline \multicolumn{4}{|l|}{ Lexical collocation } \\
\hline 1. $\mathrm{PV}+$ noun & $\begin{array}{l}\text { attacks, operations, } \\
\text { duties, mission, } \\
\text { orders, studies, study, } \\
\text { tasks }\end{array}$ & $\begin{array}{l}\text { way, answer, } \\
\text { information, secrets, } \\
\text { something, things }\end{array}$ & $\begin{array}{l}\text { marks, something, } \\
\text { areas, passage, } \\
\text { places, relationship, } \\
\text { shortcomings }\end{array}$ \\
\hline 2. noun/pronoun $+\mathrm{PV}$ & We, they, I & $I$, we, you, he, they & he, I, she, you, it, we \\
\hline 3. $\mathrm{PV}+$ that clause & - & that & that \\
\hline 4. $\mathrm{PV}+$ wh-words & - & $\begin{array}{l}\text { what, who, how, if, } \\
\text { where }\end{array}$ & how, what \\
\hline
\end{tabular}




\section{Discussion, Conclusion, and Recommendations}

\subsection{Discussion}

Grammatical Patterns of the Target Phrasal Verbs - According to the information and examples from OALD (2010), the three target PVs are syntactically transitive and separable. This means that they can take a direct object and it can be placed either after the phrasal verb, or between a lexical verb and an adverbial particle (Quirk et al., 1985). However, the current study does not focus on the separability feature of the three PVs. Most of the major patterns from this study are included in OALD (2010), while some grammatical patterns are not illustrated in OALD (2010). This may be attributed to the limited space of the dictionary or stylistic variations of PV use in users' writings or utterances, which are not covered in the dictionaries consulted, e.g., the passive voice pattern of the three PVs and the variants in the use of reported speech in the case of the PV point out.

Collocates of the Target Phrasal Verbs - With regards to the collocates of the target PVs, the high-frequency collocates obtained from this study are parts of the major grammatical patterns (carry/carries/carried/be carrying out $+\mathrm{sth}$, find/finds/found out + wh-words, and point/points/pointed out + (to sb) + that clause). The findings show that a combination of words that co-occur very frequently rather than by chance could eventually form a fixed or identifiable construction as suggested by OALD (2010), and Benson, Benson, and Ilson (2010), and would lead to a kind of natural-sounding verbal and written expression.

\subsection{Conclusion}

The following conclusions can be drawn from the data.

$>\quad$ Whereas dictionaries are great sources of word meanings, this kind of reference does not provide a comprehensive list of all grammatical patterns and collocates of any particular word. The concordance lines from language corpora could serve as a supplement to the dictionaries to explore naturally-occurring examples. On some occasions, novel aspects of language or grammatical patterns have been discovered from the qualitative analysis of the present study.

$>\quad$ Despite being under the same classification as phrasal verbs, the target words carry out, find out, and point out differ in terms of the text types in which they usually appear, grammatical patterns, and words that collocate with them.

$>\quad$ In the current study, there was a close relationship between the major collocates and the frequently-used grammatical patterns of carry out, find out, and point out.

\subsection{Pedagogical Implications}

Although teaching is not the primary concern of this study, the following could be applied to English language pedagogy.

$>\quad$ In corpus-based studies, the samples from the corpora can be used to analyze quantitatively and qualitatively to obtain diverse aspects and patterns of a language. Instead of relying heavily on intuition or dictionaries alone, teachers can benefit from corpus-based data to provide authentic language examples for their students.

$>\quad$ An inductive learning approach can be promoted by the use of language corpora. Teachers can assign students to observe patterns given by the corpora and make generalizations about language use and forms (O’Keeffe, McCarthy, \& Carter, 2007). 
Kiativutikul, C. \& Phoocharoensil, S.

\subsection{Recommendations}

Based on the findings and conclusions of this study, the following recommendations are made for future research.

$>$ In this study, the researcher employed only one American-English corpus, namely COCA, with a query of 500 concordance lines. More interesting results in terms of grammatical patterns and collocations could be discovered if a variety of corpora is used and the search includes a greater number of concordance lines.

$>$ As the meaning of PVs was not the main objective of this study, future research could focus on their semantic features.

$>$ The researcher did not query for a separability feature of the target PVs, i.e., they can have one or more words inserted between the lexical verbs and the adverbial particle. Future research may include this aspect in the investigation.

\section{References:}

Benson, M., Benson, E., \& Ilson, R. (2010). The BBI combinatory dictionary of English: Your guide to collocations and grammar (3rd ed.). Amsterdam: John Benjamins. http://dx.doi.org/10.1075/z.bbi

Celce-Murcia, M., \& Larsen-Freeman, D. (1999). The grammar book: An ESL/EFL teacher's course (2nd ed.). Boston, MA: Heinle \& Heinle.

Conrad, S. M. (1999). The importance of corpus-based research for language teachers. System, 27(1), 1-18. http://dx.doi.org/10.1016/S0346-251X(98)00046-3

Darwin, C. M., \& Gray, L. S. (1999). Going after the phrasal verb: An alternative approach to classification. TESOL Quarterly, 33, 65-83. http://dx.doi.org/10.2307/3588191

Eastwood, J. (1994). Oxford guide to English grammar. Oxford: Oxford University Press.

Gardner, D., \& Davies, M. (2007). Pointing out frequent phrasal verbs: A corpus-based analysis. TESOL Quarterly, 41(2), 339-359.

Liao, Y. D., \& Fukuya, Y. J. (2004). Avoidance of phrasal verbs: The case of Chinese learners of English. Language Learning, 54(2), 193-226. http://dx.doi.org/10.1111/j.1467-9922.2004.00254.x

Liu, D. (2011). The most frequently used English phrasal verbs in American and British English: A multi-corpus examination. TESOL Quarterly, 45(4), 661-688. http://dx.doi.org/10.5054/tq.2011.247707

Longman dictionary of contemporary English (4th ed.). (2005). Essex: Pearson Education Limited.

Macmillan English dictionary for advanced learners. (2002). Oxford: Macmillan Publishers Limited.

O'Keeffe, A., McCarthy, M., \& Carter, R. (2007). From corpus to classroom: Language use and language teaching. Cambridge: Cambridge University Press. http://dx.doi.org/10.1017/CBO9780511497650

Oxford advanced learner's dictionary (8th ed.). (2010). Oxford: Oxford University Press.

Quirk, R., Greenbaum, S., Leech, G., \& Svartvik, J. (1985). A comprehensive grammar of the English language. London, England: Longman.

Reppen, R. (2010). Historical perspective. What are corpora and how have they evolved? In A. O'Keeffe \& M. McCarthy (Eds.), The Routledge handbook of corpus linguistics (pp. 31-37). Oxford: Routledge.

Yasuda, S. (2010). Learning phrasal verbs through conceptual metaphors: A case of Japanese EFL learners. TESOL Quarterly, 44(2), 250-273. http://dx.doi.org/10.5054/tq.2010.219945

Zarifi, A., \& Mukundan, J. (2012). Phrasal verb in Malaysian ESL textbooks. English Language Teaching, 5(5), 9-18. http://dx.doi.org/10.5539/elt.v5n5p9 